\title{
Analysis of Slang Words Formation Found in the Lyrics of Drake's Songs
}

\author{
I Gede Budasi ${ }^{1}$, I Putu Abdi Bhuwana ${ }^{2}$ \\ Ganesha University of Education, INDONESIA \\ e-mail: yaysurya8@yahoo.com ${ }^{1}$, abdibhuwana28@gmail.com²
}

\begin{abstract}
This study attempts to find out the word formation process of slang words found in the lyrics of Drake's songs. This research applies descriptive qualitative research design. The theory of the 18 types of word formation process based on the synthesized theories from Yule (2010), Mattielo (2008), O’Grady, Aronoff, \& Dobrovolsky (1997) is used as guidelines. This study finds out that there were 190 slang words existing in the lyrics of the songs. They are respectively categorized into clipping (27\%), coinage (25\%), multiple process (22\%), compounding (18\%), reduplicatives $(2 \%)$, variation $(2 \%)$, borrowing (1\%), blending $(1 \%)$, acronym and initialism $(1 \%)$, reversed forms $(0.5 \%)$, and onomatopoeia $(0.5 \%)$. It can be inferred that the lyrics of Drake's songs most dominantly use slangs that are formed respectively through clipping, coinage, multiple processes, compounding, reduplicatives process, variation, borrowing, blending, acronym and initialism, reversed forms, and onomatopoeia.
\end{abstract}

Keywords: Slang; word formation; song lyrics.

\section{INTRODUCTION}

Language, in terms of its use and progress, has currently undergone rapid development. The development that happens is in terms of the vocabulary or the list of the words existing. It is found out that there exist so many new words which have never been heard or used before. These newly existing words are commonly used and invented by young users of a language. On the other hand, there are as well some of the words which undergo meaning shift. The meaning of the words after undergoing meaning shift is for most of the time quite distant. These newly invented words and meaning-shifted words are most frequently used in informal context or daily conversation. These types of words are further what people usually call slang words.

Slangs or slang words are generally defined as informal words, non-standard words or phrases which are commonly found in speech rather than in writing and are typically restricted to a particular context or group (Fromkin et al.,1974; Keraf,1984). Interestingly, some experts have different points of view of how slang words should be seen. Anderson and Trugill (1990), for example, defines slang as a bad language usage or the decay of language rather than a required change. Howard (1984) shares similar point of view. He says that slang is special vocabulary that is used by a group of low or disputable character, or simply, is a vulgar type of language. On the contrary, Keraf (1984) argues that slang words should be seen as types of purely high conversation words. It means that slang words are words that are nonstandard and informal ones which are arranged exclusively, and sometimes are the result of accidental mistakes or in the form of destructions of a common word to fill in another field meaning (Keraf, 1984). In brief, it can be assumed that all of the experts mentioned previously see slang as the non-standard words that are restricted to particular context or group and as the bad language usage.

However, it must be noted that slang words are highly accepted to be used nowadays. In fact, most of the population frequently use certain slang words which make those words achieve status and soon are accepted as our everyday language. Some examples are the slang words phone and plane that are commonly used instead of their original form of telephone and airplane.

This phenomenon is even further enhanced by the development of ICT (Information, Communication and Technology). In fact, when people communicate using ICT media like messaging, they tend to use slang words instead of the standard words. The examples of slang words that are frequently used instead of their standard forms are the slang word lol and C.U which 
respectively represent their standard words of laughing out loud and see you. This phenomenon occurs since people tend to choose simpler words which represent the same meaning rather than to use the longer ones. Slangs, as they are often simpler to be uttered and used, are then begun to be accepted to be used in daily conversation. Furthermore, according to Fromkin et al. (1974), slang is considered as the product of the development of the new words happening as a creative expression from people to make the words more efficient and simpler to be uttered. This implies that slang words as the product of human's creative expression, may vary from generation to generation and one geographical area to others. This is due to the fact that slang words will always be updated along with human development.

It is then largely accepted that during human's development, those who are in teenage stage are the most creative people in the society. They often invent their own terms in communicating with each other, which for most of the adults are incomprehensible. This fact leads to the phenomenon that most of the slang words are invented by teenagers.

Teenagers' lives, wherever they live, are the most interesting topics to be chosen in literary works. The fact that teenagers spend most of their time enjoying entertainment further supports those who work in entertainment field to take the theme of teenage life in their literary product. In addition, the most produced and consumed literary works known nowadays are music and films. Both of them commonly take the teenage life theme to attract their consumers, who are mostly in productive stages (teenagers and pre-adults). Thus, teenage life is well exploited in music and films. As the result, the terms that are once limited to teenager are now widely spread and further accepted as slangs or slang words. This fact shows that the development of music, film, and other industry of entertainment contribute to the existence of slang words.

The fact that slangs as part of teenagers' lives are included in literary works further suggests that nowadays, slang can be found not only in daily conversation, but also in lyric of song, conversation on movie, and on TV. It would be quite difficult to explain the reason behind the use of slangs in those literary works. Yet, it is unarguable to say that people believe the use of slang words in their literary work, such as songs may attract more attention of the viewers. This is supported by the discovery stating that people are fond of using slang word for its being efficient, simple and expressive. Thus, it can be stated that slangs are no longer words that are only restricted to teenagers. Yet, the use of slang, nowadays, has transformed into a mode. However, it should be noted that due to the rapid invention of slang words, there exists a phenomenon in which people do not know the history and the actual use of certain slang words. They are, instead, only able to use them without knowing the proper context of their usage.

Partridge (1970) verifies that slang is easy enough to use but very hard to write about. This correlates with the phenomena in which most people use slang yet when they are asked to define slang, they would have a hard time in doing so. This phenomenon happens due to the fact that the meaning and form of the slang itself always changes. The change happens because of the rapid invention of the slang itself. As one generation grows up, the other generation who will be in the teenage stage will surely invent new slangs either through meaning shift or the totally invented words.

Although the existence of slang is never constant and always changing, the processes of forming slang words are, however, the same as the processes of changing form and meaning of the formation of other words in the language. Linguistically, these processes are called word formation processes. Word Formation Processes are defined as the processes of creating new words and new uses of the old words or sometimes the invention of totally new words through the process. Commonly, by determining the word formation process that a word undergoes, one will be able to grasp the meaning of the words formed. Thus, as the process of forming slangs are the same as the process of forming words in a language, then it can be stated that by determining the word formation process of a slang, the meaning of it can be tracked.

One example of the famous slangs the formation of which can be tracked is the word YOLO which was popularized by Drake, an American rapper. The slang word YOLO is analyzed to undergo the word formation process of acronym. YOLO in this case stands for $Y o u$ Only Live Once. Throughout Drake's song entitled The Motto in his 2011 album, this YOLO slang word has become widely used by people, not limited to young ones, in all around the world. This shows that the development and the trend of slang words are enhanced when they are being included in song lyrics. It becomes an interesting and worth matter to explore and investigate the slang words used as well as their word formation processes in song lyrics.

There were several studies having been conducted to investigate slang words, namely; the investigation of slang words created and used in 1CAK.com site by Harared (2018) and investigation of slang words found in song lyrics of Eminem on Album Kamikaze by 
Haspo \& Rosa (2018). These previous studies investigated the word formation process using the theory proposed by Yule (2006). However, there is not any study investigating in depth the words formation processes of slang words found in Drake's songs despite Drake being the one who popularized the slang word of YOLO. Thus, this study attempts to investigate the word formation processes of slang words found in the lyrics of Drake's songs using the synthesized theory of word formation process offered by Yule (2010) and Mattielo (2008) and O'Grady, Aronoff, \& Dobrovolsky (1997).

\section{METHODOLOGY}

The research in this study were a descriptive qualitative research conducted by discussing, analyzing, and finding the slang words in the lyrics of Drake's songs. The subjects of this research were the lyrics of songs sung by Drake, namely; God's Plan, Nice for What, I'm Upset, Don't Matter to Me, In My Feelings, Nonstop and Mob Ties which are the ones from Scorpion album. Lyrics of Drake's songs that were analyzed in this research were in the form of the transcripts of the lyrics taken from online website: https://genius.com. The objects of this research were the slang words found in the lyrics of Drake songs.

There were some steps in collecting the data on this study. First of all, the lyrics were observed through scanning reading technique. The non-standard English words in the lyrics were then found during this reading process. The identified words were marked and given codes accordingly. After that, note taking was conducted towards the obtained data. In order to classify the data, a table of classification of types of slang word formation process was used as the instrument.

As for the data analysis, this research used a model of document analysis by Bowen (2009) in which the song lyrics were treated as a document and were interpreted to make a meaning. This study also used Miles and Huberman (1994) qualitative data analysis that involved cyclic process of data reduction, data display, and conclusion drawing. The result from data collection were analyzed using the theories of slang words formation proposed by Yule (2010) with 12 types, Mattielo (2008) with 15 types, and O'Grady, Aronoff, \& Dobrovolsky (1997) with 9 types which were synthesized into 18 types of slang word formation, namely, coinage, borrowing, final combining forms, reduplicatives, derivation, multiple process, elliptic rhyming slang, reversed forms, variation, compounding, blending, clipping, back formation, conversion, acronym and initialism, prefixes and suffixes, infixes, and onomatopoeia. The data obtained were analyzed, tabulated, and displayed in form of table. To show the word formation process of the data found, a further description was then provided.

\section{FINDINGS}

Based on the data collection, it is found 190 data. The 190 data arere categorized based on the synthesized theory of word formation process from Yule (2010), Mattielo (2008) and O'Grady, Aronoff, \& Dobrovolsky (1997). From 18 types of slang words formation process proposed, there are only 11 out of 18 types which are found. They are coinage, borrowing, reduplicatives, multiple process, reversed forms, variation, compounding, blending, clipping, acronym and initialism, and onomatopoeia. The details of the findings are as follows;

Table 1. Tabulation of Word Formation Processes of Slangs Found

\begin{tabular}{lrr}
\hline \multicolumn{1}{c}{ Types of Slang Words } & Number of Data & Percentage \\
\hline Coinage & 48 & $25 \%$ \\
Borrowing & 2 & $1 \%$ \\
Reduplicatives & 3 & $2 \%$ \\
Multiple Processes & 41 & $22 \%$ \\
Reversed Forms & 1 & $0.5 \%$ \\
Variation & 3 & $2 \%$ \\
Compounding & 35 & $18 \%$ \\
Blending & 2 & $1 \%$ \\
Clipping & 52 & $27 \%$ \\
Acronym and Initialism & 2 & $1 \%$ \\
Onomatopoeia & 1 & $0.5 \%$ \\
Total & 190 & $100 \%$ \\
\hline
\end{tabular}

\section{DISCUSSION}

In their study, Haspo \& Rosa (2018) who use the theory of Yule (2006) to investigate word formation of slang words in Eminem song lyrics on the album Kamikaze find out that there are only 4 out of 9 types of slang word formation. They are Clipping (50 data), Blending (6 data), Acronym (2 data) and Coinage (2 data). Using the same theory, in his research, Harared (2018) finds out that there are only 6 processes that emerge in 1cak.com site, namely; acronym, blending, borrowing, clipping, derivation, and initials.

Unlike the reviewed researches, in order to give a wider and clearer analysis as well as the form of theory triangulation, this research used the synthesized theory of slang word formation proposed by Yule (2010), Mattielo (2008) and O'Grady, Aronoff, \& Dobrovolsky (1997). In the synthesized theory, it is formulated that there are 18 types of slang words formation. They are: (1) Coinage, (2) Borrowing, (3) Final Combining Forms, (4) Reduplicatives, (5) Derivation, (6) Multiple Process, (7) Elliptic Rhyming 
Slang, (8) Reversed Forms, (9) Variation, (10) Compounding, (11) Blending, (12) Clipping, (13) Back Formation, (14) Conversion, (15) Acronym and Initialism, (16) Prefixes and Suffixes, (17) Infixes, and (18) Onomatopoeia.

From these 18 types, there are only 11 types of slang words formation found in the lyrics of Drake's songs. They are Coinage, Borrowing, Reduplicatives, Multiple Process, Reversed Forms, Variation, Compounding, Blending, Clipping, Acronym and Initialism, and Onomatopoeia.

\section{Clipping}

Clipping is defined as a word formation process that involves a deletion of one part of words to form a shorter one (Yule, 2010; Mattielo, 2008; O'Grady, Aronoff, \& Dobrovolsky, 1997). The meaning possessed by the shortened form is the same as the original one.

An example is the word Ambidextrous which is in lyrics of Drake's songs clipped into Ambidex'. Another example is the word 'round. The word 'round in the lyrics of Drake's songs is analyzed to be the clipped form of the word around. It can be seen that the process of forming word 'round involves a deletion of letter a in the beginning of word around (Around $\rightarrow$ 'round).

This research finds out that clipping is the most dominant process that appears in the lyrics of Drake's songs (52 slang words or $27 \%$ of the total data). Similarly, both Haspo \& Rosa (2018) and Harared (2018) find out that clipping process is also the most dominant process that appears in 1cak.com site and Eminem song lyrics. This finding implies that slangs that are commonly found and used nowadays are in the form of clipped form of certain words.

\section{Coinage}

Beside clipping type, this study finds further that there are 48 slang words $(25 \%)$ that undergo the coinage process.

Yule (2010) defines coinage as the process of the creation of a totally new term. Mattielo (2008) further adds that coinage or word manufactures and fanciful formations is a process of forming a word through ex nihilo (out of nothing) without morphological motivation as in Kodak. It means that the new word may be coming from a term or name that is being adapted into English without changing its form. This is supported by O'Grady, Aronoff, \& Dobrovolsky (1997) who state that coinage may be inspired by the name of things. Furthermore, it is also inferred that the words that are similar in terms of form with the standard English words but have different meaning can be categorized as the coinage type.

One example of slang words found in the lyrics of Drake's songs that belongs to this coinage type is Shorty (n) as in "I know shorty and she doesn't want no slow song" (Verse 1: Line 2, Nice for What). This slang is a totally invented word which is commonly used by the rappers. According to urbandictionary.com, the word shorty is the frequently used word by rappers to indicate an attractive woman. Another example is bands (n) as in "This shit ain't no hundred bands" (Verse 2: Line 17, Nonstop). The word bands, in the lyrics of Drake's songs, does not refer to the groups of musicians. Yet, it refers to the slang term of bands which means thousand dollars. The other example of slang words identified to undergo coinage process is bad (adj) as in "High school pics, you was even bad then" (Verse 2: Line 3, Nice for What). This slang word is a slang word that has similar form with the adjective bad in standard English. However, as a slang in the context of Drake's songs, it has different meaning, that is, good looking.

Coinage process also appears in the research conducted by Haspo and Rosa (2018). However, it does not appear in the research conducted by Harared (2018).

\section{Multiple Processes}

The next type of word formation processes that can be identified in the lyrics of Drake's songs is multiple processes. There are 41 (22\%) slang words undergoing this multiple processes.

Yule (2010) states that a word may undergo more than one types of word formation processes. This type is called multiple processes.

The example slang word of this type is Tryna as in "They keep tryna get me for my soul" (Verse 2: Line 1, I'm Upset) which undergoes several word formation processes, namely: Blending and Variation, as follows:

Trying (v) + to $(\mathrm{p}) \rightarrow$ Tryna (v) (Blending)

$$
\text { *To }(\mathrm{p}) \rightarrow \text { na (Variation). }
$$

Thus, it is categorized into slang word that belongs to multiple processes type. Another example is the word gon' as in "They gon' tell the story, shit was different with me" (Verse 1: Line 8, God's Plan). The word gon' undergoes several types of word formation processes, namely: Clipping, Blending and Variation.

$$
\begin{aligned}
& \text { Gonna (v) } \rightarrow \text { Gon' (v) } \\
& (\text { Clipping) } \\
& * \text { Going (v) }+ \text { to }(\mathrm{p}) \rightarrow \text { Gonna (v) (Blending) } \\
& * * \text { to }(\mathrm{p}) \rightarrow \text { na }(\text { Variation })
\end{aligned}
$$


Thus, it is categorized into slang word that belongs to multiple processes type

\section{Compounding}

There are 35 slang words (18\%) which belong to the category of slang words that underwent the compounding process.

Compounding process is defined as the process of forming a word by joining two or more words to produce a single form (Yule, 2010; Mattielo, 2008; O'Grady, Aronoff, \& Dobrovolsky,1997).

One example of slang words found in lyrics of Drake's songs that belongs to this compounding type is Dark days as in "You know dark days, you know hard times" (Verse 2: Line 9, Nice for What). The slang word of Dark Days in the lyrics of Drake's songs is not defined as days that are dark. Yet, it is defined as a bad occurrence that has happened. Another example is first-last (n) as in "first-last, phone bill, car note, cable" (Verse1: Line 8, Nice for What). The combined form of first-last is a compounding word which does not mean the first and the last as the meaning of the parts forming it. Yet, the word first-last in the context of Drake's songs means rent payment that must be paid.

\section{Reduplicatives}

In term of reduplicatives process, it is found out that there are 3 slang words (2\%) identified in the lyrics of Drake's songs undergoing this process.

According to Mattielo (2008), reduplicatives can be defined as the process of forming a word in which it is characterized by the existence of repeated constituents. Mattielo (2008) further adds that there are 4 main patterns of reduplicatives namely; ablaut (i.e tik-tok), rhyming reduplicatives (i.e. fuzzy-wuzzy), rhyming compounds (i.e. funny bunny), and identical constituents (i.e. byebye).

One example of slang words identified in the lyrics of Drake's songs that represent this type of slang word formation process is fifty-fifty as in "Can't go fifty-fifty with no hoe" (Verse 1: Line 4, Nice for What). This slang word is identified to undergo reduplicatives especially the identical constituents pattern. The meaning of this slang word is to divide/split/share something. Another example is the word Lovey-dovey $(\mathrm{adj})$ as in "It's too late for all that lovey-dovey shit" ( $1^{\text {st }}$ chorus: Line 5, Mob Ties). The slang word loveydovey is categorized as slang words that undergo the reduplicatives specifically rhyming reduplicatives. It is since neither lovey nor dovey does possess a meaning if it stands alone. Both constituents (lovey and dovey) are also rhyming (sharing similar sounds). The meaning of this reduplicative in the lyrics of Drake's songs is affectionate and romantic.

\section{Variation}

Furthermore, it is inferred that there are 3 slang words (2\%) that underwent the variation process.

Mattielo (2008) explains that variation is a mechanism of forming a slang in which there is a process of modification of a word base by varying (part of) the spelling.

One example of slang words that belongs to this type in the lyrics of Drake's songs is $Y a$ as in "Cause I want $y a$, and I need $y a$ " (Chorus: Line 3, In My Feelings). The slang word $y a$ in this context is the variation of word you. The part ou in the word You is changed into $a$ making it to form a new form of $y a$ which means You. Another example is the word hunnid as in "Hunnid thousand on my head, it's disrespect (disrespect)" ( $2^{\text {nd }}$ Chorus: Line 2, I'm Upset). The word hunnid here is analyzed to be originated from the word hundred. The spelling of word hundred is altered by changing the part dre into $n i$ making it into a new form of hunnid. This new word of hunnid is still possessing the same meaning as its previous form of hundred. Thus, it is stated to undergo variation process.

\section{Borrowing}

The next identified process of slang words formation in the lyrics of Drake's songs is the borrowing process with 2 data $(1 \%)$.

Yule (2010) defines borrowing as the process of word formation by taking over the words from sother languages. Yet, in further elaboration it is stated that the borrowed terms are not limited from a language of society but also a language of a certain subject, like chemistry, biology, or economy.

The slang words identified or the data that belong to this type in the lyrics of Drake's songs are the slang words $O 2$ and $O 3$ as in "Turn the $O 2$ into the $O 3$, dog" (Verse 2: Line 6, God's Plan). Originally, both $\mathrm{O}_{2}$ and $\mathrm{O}_{3}$ are abbreviations in chemistry. $\mathrm{O}_{2}$ refers to the existence of 2 atoms of Oxygen in the Oxygen, while $\mathrm{O}_{3}$ represents the existence of 3 atoms of Oxygen in the Ozone.

The borrowing process was found to also appear in the research conducted by Harared (2018). 


\section{Blending}

Like borrowing, there are also 2 slang words (1\%) identified in the lyrics of Drake's songs that undergo the blending process.

Blending itself is defined as a process of forming a new word by combining two separate forms to produce a single new term (Yule,2010; Mattielo,2008; O'Grady, Aronoff, \& Dobrovolsky,1997). However, unlike compounding, blending is accomplished by taking only the beginning of a word and joining it to the end of other words.

The data or the slang words identified in the lyrics of Drake's songs that belong to this type are the slang words y'all as in "A song for y'all to cut up to, you know?" (Chorus: Line 8, Nice for What) and gimme as in "Gotta gimme that shit, dog" (Verse 2: Line 5, Nonstop). The former is derived from the combination of word you and all. The process involves the elimination of $o u$ in the word you. Meanwhile, the latter is derived from the combination of word give and me. The process further involved the elimination of $v e$ in the word give and the addition of infix $m$.

Blending process also appeared in the research conducted by Harared (2018) as well as Haspo and Rosa (2018).

\section{Acronym and Initialism}

The next word formation process of the slang words identified in the lyrics of Drake's songs is acronym and initialism process. There were 2 data $(1 \%)$ found representing this type of slang word formation.

Acronym and initialism can be defined as the process of forming a new word by combining the initial letters of the words forming it (Yule,2010; Mattielo,2008; O’Grady, Aronoff, \& Dobrovolsky,1997).

The first slang word or data that belongs to type is R.I.P. as in 'They'll be mournin' you like $8 \mathrm{AM}$ (R.I.P)" (Verse 2: Line 10, Nonstop). This slang word is formed by taking and combining initial letters $(\mathrm{R}, \mathrm{I}$, and $\mathrm{P}$ ) of a term Rest in Peace. The existence of period (.) in this case is the indicator of the process of acronym. The slang word identified in the lyrics of Drake's songs that is categorized into this type is $S M S$ as in "SMS, triple X" (Verse 2: Line 7, I'm Upset). The slang word SMS represents the term Short Message Service. The initial letters of the term (S, M and S) are taken and combined to coin a new term of $S M S$ which still represents meaning of the original form. In this case the slang word SMS has been widely used nowadays to represent the messaging service provided by the phone or cellular service.

\section{Reversed Forms}

The next process of word formation of slang words in the lyrics of Drake's songs is reversed forms. There is however only one slang word representing this type.

Mattielo (2008) elaborates that reversed forms are slang words that can be read reversely. Reading reversely here means that if the slang word is written backwards (rewriting it down from the last letter to the first one), it will possess a different meaning from the previous writing.

The slang word that belongs to this process is $d o g$ as in "Like I went blind, $d o g$, you gotta hand it to me" (Verse 2: Line 4, Nonstop). This slang word of $d o g$ does not represent the literal meaning of $\operatorname{dog}$ (a pet) itself. Instead, the slang word $d o g$ in the context of lyrics of Drake's songs represents the word God. The original word of God is written backward into dog.

\section{Onomatopoeia}

The last process of the formation of slang words found in the lyrics of Drake's songs is onomatopoeia. Like reversed form, there is also only one slang word representing this type of word formation.

Onomatopoeia, according to O'Grady, Aronoff, \& Dobrovolsky (1997), is defined as a process of word formation in which the word created is formed by imitating the sound of the thing that they name.

The slang word that belong to this word formation process is the slang word shush as in "Heard all of the talkin', now it's quiet, now it's shush (shh)" (Verse 2: Line 3, Mob Ties). The slang word shush is the slang word that undergo the process of onomatopoeia because it imitates the sound produced when someone's asking others to be quiet that is the sound of shhh.

The analysis above shows that the word formation process of the slang words identified in the lyrics of the Drake's songs is in line with the theory proposed by Mattielo (2008) rather than the ones proposed by Yule (2010) and O'Grady, Aronoff, \& Dobrovolsky (1997). The analysis also shows that out of fifteen types of word formation process proposed by Mattielo's theory (2008), eight types are found in the lyrics of Drake's songs.

\section{CONCLUSION}

This study shows that there are 190 slang words identified in the lyrics of Drake's songs. Out of 18 types of slang words formations based on the 
synthesized theory of Yule (2010), Mattielo (2008) and O'Grady, Aronoff, \& Dobrovolsky (1997), there are 11 types found in the lyrics of Drake's songs. They are coinage, borrowing, reduplicatives, multiple process, reversed forms, variation, compounding, blending, clipping, acronym and initialism, and onomatopoeia. The result of the analysis shows that out of 190 identified slang words, 52 slang words (27\%) are formed through clipping process, 48 slang words undergo coinage process (25\%), 41 slang words (22\%) are composed through multiple processes, 35 slang words $(18 \%)$ are composed through compounding process, 3 slang words $(2 \%)$ are formed through reduplicatives process, 3 slang words (2\%) undergo variation process, 2 slang words (1\%) undergo borrowing process, 2 slang words (1\%) are formed through blending process, 2 slang words (1\%) undergo acronym and initialism process, 1 slang word $(0.5 \%)$ is formed through reversed forms process, and 1 slang word $(0.5 \%)$ is formed through onomatopoeia process. It can be inferred that the lyrics of Drake's songs most dominantly use slangs that are formed respectively through clipping, coinage, multiple processes, compounding, reduplicatives process, variation, borrowing, blending, acronym and initialism, reversed forms, and onomatopoeia.

\section{REFERENCES}

Adi, W., \& Azmi, A. (2018). Slang expression in Little Man movie based on social dimension. Lingua, 15(2), 97-113. doi: 10.30957/lingua.v15i2.480.
Allan, K., \& Burridge, K. (2006). Forbidden words: taboo and the censoring of language. New York: Cambridge University Press.

Anderson, L., \& Trudgill, P. (1990). Bad language. New York: Penguin Group Incorporated.

Bowen, G. (2009). Document analysis as a qualitative research method. Qualitative Research Journal, 9(2), 27-40. doi: 10.3316/QRJ0902027.

Fromkin, Victoria, \& Robert, R. (1974). An Introduction to language. 2nd Australian edition. New York: Holt Rinehart and Winston Inc.

Harared, N. (2018). Slang created and used in 1CAK.COM Site: A sociolinguistics study. Humaniora, 9, 119 - 127.

Haspo, F., \& Rosa, R. (2018). An analysis of slang word in song lyrics Eminem on album Kamikaze. E-Journal of English Language \& Literature, 7, 523-526.

Howard, P. (1984). The state of the language. London: Hammis Hamilton.

Keraf, G. (1984). Diksi dan gaya bahasa. Jakarta: Gramedia Pustaka Utama.

Mattiello, E. (2008). An introduction to English slang: A description of its morphology, semantics and sociology. Milano: Polimetrica.

Miles, M., \& Huberman, A. (1994). Qualitative data analysis. 2nd Ed. Newbury Park: CA: Sage.

O'Grady, W., Aronoff, M., \& Dobrovolsky, M. (1997). Contemporary linguistics: An introduction. New York: St. Martin Press.

Partridge, E. (1970). Slang Today and Yesterday. London: William Press.

Yule, G. (2010). The study of language. 4th Ed. Cambridge: Cambridge University Press. 